\title{
Do modelo asilar-manicomial ao modelo de reabilitação psicossocial - haverá um lugar para o psicanalista em Saúde Mental?*
}

Nancy Greca de Oliveira Carneiro

\begin{abstract}
Da desrazão ao doente mental e ao portador de transtorno mental, embora se operem deslocamentos importantes nas Instituições de Saúde Mental, o sujeito permanece excluído. Discute-se a proposta de uma instituição que possa sustentar a lógica do não todo, do caso a caso, onde não se pode escrever o universal ou formar conjunto. Apresenta-se a psicanálise aplicada ao campo da saúde mental como uma clínica do sujeito, fundada não na diversidade, mas na singularidade de sua relação com seu desejo e seu gozo.

Palavras-chave: Psicanálise splicada, lógica do não-todo, clínica da psicose, sujeito suposto não saber
\end{abstract}

* Este artigo é efeito da clínica psicanalítica aplicada à terapia e de observações organizadas ao longo do trabalho enquanto Supervisora de Estágios de alunos do Curso de Psicologia da PUC-PR em Instituições de Saúde Mental da cidade de Curitiba e do trabalho de orientação de Monografias dos Cursos de Especialização Lato Sensu Saúde Mental, Psicopatologia e Psicanálise e Psicologia Clínica - Abordagem Psicanalítica. 


\section{Introdução}

A questão da loucura e seu longo, persistente e complexo sistema de segregação se sustenta em uma significação que se mantém constante nas sociedades modernas, apoiadas na construção do mito do individual e nas fronteiras fortemente estabelecidas entre o público e o privado: a loucura é temida porque ameaça a própria natureza do social. Em uma grande instituição psiquiátrica de Curitiba, durante uma gestão que procurava reestruturar o sistema a novos modelos de convivência, processo que produz reações em todos os níveis hierárquicos, um jovem psiquiatra exclama: Isto está parecendo uma casa de loucos! Ao que um de seus colegas de equipe retruca: Mas isto é uma casa de loucos, doutor!

A história institucional da loucura é produto de uma série de deslocamentos que culmina no movimento da Reforma Psiquiátrica que pretende desinstitucionalizar a loucura por meio de seu projeto de atenção psicossocial. Muitos são os trabalhos acadêmicos que se têm produzido no sentido de insistir no inegável avanço deste modelo em relação ao trágico processo de institucionalização da loucura que se inicia na tríade manicômio/alienista/alienado promovida pelo alienismo do século XIX. Este segue, quase intacto, na tríade hospital psiquiátrico/ psiquiatra/doente mental que, ao longo do século XX, vai criando espaço, por meio das conhecidas Comunidades Terapêuticas, para a sucessiva incorporação de outros profissionais. O processo de institucionalização da loucura vem finalmente encontrar sua necessá- 
ria desconstrução no atual modelo de atenção psicossocial/trabalhador de saúde mental/portador de transtorno mental.

A nós, psicanalistas, por muito tempo isolados das instituições pela prática privada de nossos consultórios, cabe interrogar qual o lugar do sujeito nas atuais políticas de saúde, por meio de uma reflexão sobre quais seriam as contribuições da psicanálise para a atenção à saúde mental. Ao se colocar a questão do sujeito, do particular de cada caso, no campo da Saúde Mental, pretendo situar que a clínica das psicoses impõe uma modificação das relações com o saber e a possibilidade de acompanhar o psicótico na "lógica das soluções", das invenções do psicótico para situar-se no campo da realidade. Com isto se introduz um terceiro modelo de atenção que nomeamos como instituições enquanto exceção. ${ }^{1}$ Ao longo de mais de 12 anos como professora responsável pelo ensino em Psicopatologia, coordenadora e supervisora de estágios básicos e profissionalizantes na área da Psicologia Clínica e orientadora de pesquisa em cursos de especialização em instituições de Saúde Mental, pude isolar um fenômeno anunciado pelos psicanalistas como "morte da clínica", diante do qual procuro indagar acerca do possível lugar para o psicanalista em Saúde Mental, fazendo uso da lógica do nãotodo ${ }^{2}$ lacaniano, articulada por Miller (1994).

\section{Do modelo asilar-manicomial à psiquiatria clássica}

Nos asilos do século XIX, a direção do médico, que acumula os poderes administrativos, executivos, jurídicos e liberais (terapêuticos), é agente das sínteses morais (Pessotti, 1996). De acordo com Foucault (1968), o essencial é que o asilo fundado para o internamento, na época de Pinel, não representa ainda a "medicalização" de um espaço social de exclusão, e sim a confusão no interior de um regime moral único cujas técnicas coercitivo-punitivas tinham um caráter de precaução social. O século XIX caracteriza-se, então, por uma política de saúde mental com poucos elementos: um esforço classificatório (alienismo), uma tecnologia de intervenção (tratamento moral e tratamento físico), uma organização institucional (os manicômios e os profissionais - psiquiatras e pessoal auxiliar) e o usuário (o louco que, na lei de 1838, se define como tutelado pelo Estado) (Carneiro, 2000).

1. O termo "instituição enquanto exceção" é um conceito desenvolvido na sessão clínica do Instituto Psiquiátrico Raul Soares, de Belo Horizonte, Minas Gerais.

2. O texto "Homologue de Malagua" está traduzido para o português com o título: "A lógica da direção da cura psicanalítica". 
No início do século XX, ocorrem duas rupturas de natureza epistemológica: as hipóteses de uma sintomatologia suscetível de ser descrita como doença, representada pela psicopatologia moderna, e de uma sintomatologia suscetível de ser decifrada em seu sentido simbólico, dada pela psicanálise, constituem os campos da psiquiatria moderna e da psicanálise. Em meados do século XX, o acelerado desenvolvimento tecnológico, associado à intensa produção de medicamentos, resulta no avanço da psicofarmacologia e em uma série de deslocamentos da psiquiatria institucional para a prática liberal das psicoterapias. Paralelamente, a prática liberal da psicanálise e das psicoterapias emergentes retiram sistemática e definitivamente dos manicômios as neuroses, integrando-as na subjetividade do homem moderno e estreitando o conceito de doença mental em torno das psicoses e da presença de alucinação e delírio. ${ }^{3}$

Neste contexto, surgem os hospitais psiquiátricos clássicos, onde a instituição se organiza em uma série de disposições graduadas em torno das enfermarias, unidades administrativas denominadas "serviços", e da possibilidade de o paciente vir a ter "alta". Nessas instituições já é possível encontrar vários serviços chamados de "paramédicos", como os de enfermagem e de assistência social.

Quando as concepções organicistas se impuseram sobre o tratamento moral de forma mais definitiva, a prescrição de neurolépticos, nas primeiras décadas do século XX, permitiu a hospitalização do espaço moralizador. A internação em um "estabelecimento especial" é o elemento determinante que condiciona esse status, descrito por Kraepelin como "entidades mórbidas". Para Castel (1978), a "medicalização" não significa, de fato, a simples confiscação da loucura por um olhar médico. Ela implica a definição, por meio da instituição médica, de um novo status jurídico, social e civil do louco: o doente mental. Portanto, o essencial na medicalização da loucura não é a relação médico-doente, mas a relação medicina-hospitalização, o desenvolvimento de uma tecnologia hospitalar, o desenrolar de um novo tipo de poder na instituição, a aquisição de um novo mandato social a partir de práticas centradas no modelo hospitalar. Ficam cortadas as vias para a assistência a domicílio, para a confiança no valor terapêutico dos vínculos familiares e das relações não profissionais. A hospitalização torna-se a única e necessária resposta ao questionamento da loucura. O tratamento é assentado quase que exclusivamente em técnicas coercitivo-punitivas inicialmente exercidas pelo

3. Utilizo aqui o conceito de delírio, do ponto de vista psiquiátrico, por considerá-lo um conceito-chave na percepção social da loucura. Assim, delírio é definido como "erro de apreciação da realidade, de origem mórbida, que surge como uma evidência 'a priori' (convicção independente da experiência), mesmo quando está em contradição com o real comum, com as opiniões e crenças coletivas" (AMDP - Sistema de documentação e quantificação em psicopatologia). M. Paes de Souza, 1985. 
pessoal auxiliar e na administração de psicofármacos em instituições descritas como "instituições totais", por Goffman (1990).

Nas décadas de 1960/1980, se processam novas rupturas, agora de natureza política, na ordem institucional. O movimento antipsiquiátrico apresenta uma contundente crítica à psiquiatria institucional que questiona seus próprios métodos e reivindica para loucura um novo status existencial (Laing; Cooper, 1969). A idéia de comunidade terapêutica em que "todos curam" dá lugar à ação da equipe multidisciplinar, rompendo com a exclusividade do modelo médico-psiquiátrico e incorporando profissionais de diversas áreas (psicólogos, terapeutas ocupacionais, sociólogos etc.). Inaugura-se, assim, o conceito de trabalhador em Saúde Mental (Baságlia, 1978). Estas instituições tendem ao uso de técnicas de natureza persuasivo-manipulatórias (sofisticados sistemas de punição e recompensa) em vez do uso de técnicas de natureza coercitivo-punitivas, base do tratamento moral do século XIX.

Interessa-me sublinhar que, do alienismo à psiquiatria clássica, o alienado foi radicalmente calado: sua fala foi descrita como balbucio, seu silêncio como mutismo, sua negativa como negativismo, seus gestos vigiados sob suspeita. Os intensos efeitos de exclusão produzidos pelos mecanismos de segregação social e a sistemática retirada de sentido do discurso delirante têm destituído aqueles, acusados de loucura, da posição de sujeito de sua fala, tanto em sua acepção passiva como ativa, ou seja, de sujeito como objeto daquilo que fala e de sujeito enquanto produtor de uma mensagem para um outro.

\section{Das comunidades terapêuticas à reabilitação psicossocial}

O sistemático processo de exclusão da loucura, materializado nos muros, nas grades, nas faixas e nas técnicas de controle, impediu tais sujeitos de estabelecerem relações em suas comunidades de origem; também não foi sem efeitos no interior destas mesmas comunidades e das famílias, por sua vez impedidas de, com ele, estabelecerem laços de convivência, sendo mantidas à distância e no desconhecimento absoluto das várias formas desta trágica experiência. $\mathrm{O}$ saber fazer com o louco se expressa para todos: lugar de louco é no hospício.

Em sua conferência sobre Saúde Mental e Ordem Pública, Jacques-Alain Miller (1999) afirma que "a saúde mental não tem outra definição que a da ordem pública” (p. 20-21). A reforma psiquiátrica, ao propor a circulação dos pacientes nas ruas da cidade, exige o reconhecimento de sua cidadania. No decorrer do processo de implantação do Serviço de Residências Terapêuticas na região metropolitana de Curitiba, o secretário de saúde do município, diante da resistência dos 
moradores vizinhos afirma: Eu tenho de pensar nos meus municipes. Ao que o técnico de referência da Residência responde: Mas senhor, os moradores da SRT são seus munícipes.

Esse sujeito deve ser chamado a ocupar o seu lugar do ponto de vista ocupacional, de sua subjetividade e, sobretudo, do ponto de vista jurídico, como um sujeito com direito à cidadania e a seu exercício. "A desinstitucionalização torna-se, portanto, um processo, a um só tempo, de desconstrução dos saberes e práticas psiquiátricas, e de invenção prático-teórico de novas formas de lidar, não mais com a doença, mas com o sujeito doente" (Amarante, 1996, p. 95).

Evidencia-se a necessidade de se conduzir à reabilitação em dois sentidos: um sentido que poderemos nomear como de reabilitação social, que assimila o sujeito do ponto de vista ocupacional ou mesmo de consumidor, e um segundo sentido que chamaremos de reabilitação jurídica, em que o sujeito se reconstrói ou se constrói como um sujeito de direito, direito pleno à cidadania e a seu exercício. As atuais políticas de saúde propõem o modelo psicossocial para a atenção à saúde mental: uma descentralização dos serviços e uma rede de assistência que inclua domicílio, unidade de saúde, recursos comunitários, pronto-atendimento, ambulatório, oficina terapêutica, centro de atenção psicossocial (CAPS), hospital-dia, hospital integral, residência terapêutica e hospital geral, organizado em uma rede horizontal.

\section{Da cidadania do indivíduo psicossocial ao sujeito do inconsciente}

O discurso psiquiátrico (CID-10; OMS, 1993, p. 5), que na atualidade reafirma cada vez com maior convicção as perturbações mentais como transtornos, encontra-se hoje esvaziado de seu sentido moral e estigmatizante. O diagnóstico psiquiátrico não se apresenta na função de imputação de culpa, significando antes, ao portador de transtorno mental, que ele tem um transtorno que como outro qualquer necessita de tratamento. ${ }^{4}$ Num trabalho realizado junto a grupos de auto-ajuda, intitulados Psicóticos Anônimos, pude constatar a presença de uma formação discursiva que se resume em poucos elementos: “... a doença mental não tem cura mas tem tratamento e este deve ser contínuo" (Carneiro, 2000, p. 57).

4. É importante observar o abandono sistemático que no desenvolvimento do DSM (Manual Diagnóstico e Estatístico de Transtornos Mentais) atualmente no n. IV, e no CID-10 (Classificação Internacional das Doenças) se vem realizando no sentido de eliminar as descrições de "entidades mórbidas" e criar uma nova nomenclatura de transtornos mentais baseada em evidências empíricas em que as questões etiológicas estão ausentes. 
Restituída ao campo médico pelo binômio medicação/resolução do problema, a psiquiatria se restringe ao tratamento medicamentoso e se retira do dia a dia das instituições deixando aos outros técnicos da Saúde a condução do projeto terapêutico, cuja natureza psicossocial anuncia uma "morte da clínica".

Uma reabilitação psicossocial que tome o sujeito apenas em sua dupla acepção social e jurídica e que ignore a motivação clínica da existência da instituição, promove uma exclusão da clínica. Na ausência de uma clínica que considere as diferentes subjetividades e, mais ainda, uma clínica das psicoses e o que esta nos impõe de confrontação com o impossível, culmina em uma prática assistencial capturada num viés puramente disciplinar que segue desconsiderando a singularidade dos sujeitos em questão. Desconsiderar a estruturação do sintoma incentiva um certo não saber o que fazer com o sintoma, e reabilitar o louco seria, nesses termos, no extremo, fazer dele um não-louco (Barreto, 2002). A demanda analítica exige mais: implica querer tratar o sintoma não só como sofrimento ou como sinal de doença, mas como enigma que ele representa, ou seja, querer saber sobre o sintoma. Com Freud, o sintoma é determinado a partir do inconsciente e, com isso, fica demonstrado que os processos psíquicos obedecem a princípios próprios, independentes dos biológicos. Funda-se uma nova clínica, a clínica psicanalítica, cuja raiz universal é a inserção do sujeito na experiência da palavra, e rompe radicalmente com o organicismo e o moralismo da psiquiatria. "A clínica psicanalítica soube entrever, nas malhas da estrutura clínica, o sujeito em sua particular existência, ou mais precisamente, o sujeito do inconsciente e sua transferência" (Barreto, 1999, p. 106).

Entre a clínica psicanalítica e a clínica psiquiátrica houve, ao longo do século XX, um processo de continuidade e de ruptura. Continuidade com a apropriação de termos, de categorias nosológicas, do trabalho com a linguagem, a ponto de se poder considerar a psicanálise como herdeira da tradição clínica da psiquiatria. Ruptura epistemológica no que determina uma clínica do sujeito situada no campo de uma ética: a do desejo.

No entanto, o dispositivo psicanalítico constituído no tratamento de neuróticos não pode ser diretamente aplicado no dispositivo institucional em que nos defrontamos com sujeitos em situação de errância, marcados pelas passagens ao ato e pelo uso de álcool e drogas, a presença de fenômenos elementares que nos exigem uma confrontação com o real da clínica. ${ }^{5} \mathrm{Na}$ psicose, o sujeito dispensa

5. A reviravolta provocada por Lacan pelo enunciado "não recuar diante das psicoses" tem implicações teóricas e clínicas, passando-se da aplicação da psicanálise à psicose à aplicação da psicose à psicanálise. $\mathrm{O}$ sujeito psicótico assume a posição de objeto do gozo de um Outro absoluto e consistente que implica, no segundo ensino de Lacan, uma clínica do real que possa dar lugar às diferentes modalidades do retorno no real da pulsão. 
o enquadramento analítico e clínico tradicional, o inconsciente "a céu aberto exige uma reviravolta que tem implicações teóricas e clínicas, passando-se da aplicação da psicanálise à psicose à aplicação da psicose à psicanálise" (Zenoni, 2000, p. 19). Em poucas palavras: é a psicose que nos ensina sobre a estrutura e sobre as soluções que ela própria encontra para uma falta central no simbólico: o que não se registra no simbólico retorna no real (Lacan, 1998).

\section{O que nos ensinam os psicóticos?}

Ao introduzir o dispositivo psicanalítico como estratégia de intervenção clínica, nas instituições em geral e nas instituições de saúde mental em particular, é necessário abrir espaço na instituição para o sujeito da palavra, introduzir o particular do sujeito no universal da instituição. Como incluir na lógica do lugar para todos, da instituição, a lógica psicanalítica que supõe a singularidade do sujeito em que cada um é um. Como introduzir no universal da instituição, o particular do sujeito?

"Ao operar o ato que cria a palavra, surge um tempo de uma clínica de exceção, da instituição enquanto exceção, ou seja, toma-se a instituição enquanto lugar do Outro que pode responder, de maneira diferente e única, à demanda reiterada do sujeito" (Alkmin, 2003, p. 44-45). Esse enquadre só é possível à medida que se reconhece o sintoma como uma resposta da relação do sujeito com o Outro. Se, com Freud, o delírio é a invenção do sujeito para se haver com a experiência psicótica, para Lacan o delírio é um saber não suposto, mas realizado pelo próprio sujeito como sua referência ao gozo. ${ }^{6}$

Antonio Di Ciaccia (1999) faz duas observações que me interessa sublinhar:

- O paciente já chega à instituição com um trabalho psíquico iniciado e este trabalho independe dos limites espaciais e temporais de uma sessão.

- Os pacientes se dirigem sobretudo àqueles que nada sabem.

A conseqüência é a inversão da suposição de saber, que poderia ser formulada nos seguintes termos: o psicótico sabe o seu caminho e a transferência se estabelece não com o suposto saber, mas com aquele que nada sabe. O delírio é um saber e o psicótico sabe encontrar as suas soluções posto que o seu caminho é autoconstruído, e impõe que possamos segui-lo no seu trabalho subjetivo.

6. O segundo ensino de Lacan opera deslocamentos de uma clínica do sentido na direção de uma clínica do real que permite pensar o Grande $\mathrm{O}$ em sua dupla dimensão de regulação e de referência aos modos de gozo. 
O que nos coloca em posição de aprendizagem em relação à clínica, em posição de sujeito suposto não-saber. Diferentemente do neurótico que situa o analista como um suposto saber sustentado na seletividade do amor, o psicótico pode tomar qualquer um e a possibilidade de acolhimento do sujeito por diferentes técnicos, permite e deve facilitar o esfacelamento do Outro.

Ora, o projeto terapêutico concebido na inspiração do projeto psicossocial se constrói sob uma suposta unidade biopsicossocial alcançada pela convergência de vários saberes. Introduzir o paciente em um projeto terapêutico construído por um sujeito que sabe saber instituído na lógica do igual para todos, numa lógica do todo. Em uma reunião de técnicos de saúde mental, um psicólogo afirma a importância da integração da equipe: cada um de nós reconhece uma parte do elefante e todos juntos poderemos fazer representar o elefante todo.

A orientação psicanalítica, ao propor uma prática feita por muitos ${ }^{7}$ sublinha a variedade das intervenções e não a quantidade/totalidade de saberes.

O fundamental nesta prática é a transmissão feita entre os participantes da equipe do que se passa na relação com a criança e que vai tendo efeito na intervenção dos outros. O trabalho de transmissão a que todos estão submetidos instaura o não todo no funcionamento daqueles profissionais... (Rego Barros, 2003, p. 70)

No cotidiano de uma instituição, um paciente comparece munido dos aparatos necessários para uma rodada de Chimarrão. Imediatamente é cercado por outros pacientes e o ambiente se torna uma confusão de alegria contagiante, disputa voraz pelo objeto. A equipe, detentora de um saber todo, imediatamente se reúne na tentativa de "organizar a atividade": a invenção possível de Um é imediatamente anulada pela norma. Ora,

... esses saberes da equipe de nada valerão se não puderem ser articulados a algo que venha do sujeito, a algo que ele nos transmita na sua fala. (...) deixar em suspenso este saber constituído que dispomos para darmos ouvidos a um saber muito particular que venha a ser construído pelo sujeito em sua relação com o Outro, a equipe. (Lucena Fernandes, 2005, p. 39)

Se o saber está do lado do psicótico, não há lugar no tratamento, do lado do analista, para nenhuma tentativa de envio a outro sentido, nenhum deciframento ou interpretação. A interpretação está do lado do psicótico, e cabe

7. A prática feita por muitos, indicada por Elisa Alvarenga como tradução a pratique à plusieurs, foi concebida por Jacques-Alain Miller para designar a prática da psicanálise nas instituições de Saúde Mental e sua necessária conversação com outros dispositivos presentes neste domínio, tais como a psiquiatria, o serviço social, a psicologia, o sistema judiciário entre outros. 
ao analista escutar as indicações que o psicótico traz para o seu caso. Dado que o psicótico sabe seu caminho, o lugar do psicanalista se desloca da posição de suposto saber para a posição de suposto não saber, passa a ser o de uma testemunha do duplo trabalho do paciente psicótico, ${ }^{8}$ de autodefesa e de autoconstrução (Viganó, 2004).

Essa clínica que privilegia o sujeito e o saber que o delírio comporta, traz a psicanálise ao campo da saúde mental e oferece indícios para uma instituição de exceção. Desta forma, de acordo com Barreto, quando se fala em clínica de exceção a pretensão é levar o discurso analítico ao serviço público, no campo da saúde mental. É importante advertir que não se trata de psicanálise pura, mas de psicanálise aplicada. Também não se preconiza o tratamento de todos os pacientes com o discurso analítico. Longe disso. O serviço público, como toda instituição, é ou deveria ser, o lugar de muitos discursos. "O que se procura é situar o discurso analítico no serviço público como um entre outros" (Barreto, 2002, p. 10).

Essa proposta de uma psicanálise aplicada ao campo da saúde mental, embora tenha como ponto de partida o sintoma, como faz a psiquiatria, trabalha visando não sua eliminação, mas certa reconciliação do sujeito com o sintoma e com o saber que o delírio comporta. Em vez de tratamento do sintoma, tratamento pelo sintoma. O que implica uma mudança na relação do sujeito com o seu gozo, numa perspectiva ética que se distancia da moral e que se realiza no caso a caso. Conseqüentemente, o discurso analítico se insere na lógica do não-todo, do caso a caso, onde não se pode escrever o universal. Se cada sujeito é diferente do outro, cada caso também o é, assim como cada tratamento. O que funda um tratamento não é uma lei universal, mas uma construção que se faz uma a uma.

\section{Referências}

Alkmin, W. Construir o caso clínico, a Instituição enquanto exceção. Almanaque, Belo Horizonte, n. 9, nov. 2003.

Amarante, P. O homem e a serpente. Rio de Janeiro: Fiocruz, 1996.

BARRETO, F. P. A psicanálise aplicada ao campo da saúde mental: uma contribuição ao

8. Carlo Viganó afirma que o psicótico trabalha o tempo todo: por encontrar-se fora do simbólico, deve defender-se do Outro que se apresenta persecutório e enigmático, e por encontrar-se fora do discurso, mas não fora da linguagem, ocupar-se da construção de um mundo simbólico de suplência. 
tema da prática nas instituições. Apostila cedida pelo autor ao Curso de Saúde Mental, Psicopatologia e Psicanálise da PUC-PR, 2002.

. Reforma psiquiátrica e movimento lacaniano. Belo Horizonte: Itatiaia, 1999.

Baságlia, F. A psiquiatria alternativa: contra o pessimismo da razão, o otimismo da prática. São Paulo: Brasil Debates, 1978.

BRASIL. Ministério da Saúde. Secretaria Executiva. Secretaria de Atenção à Saúde. Legislação em saúde mental: 1990-2004. 5. ed. ampl. Brasília: Ministério da Saúde, 2004.

. Ministério da Saúde. Secretaria de Atenção à Saúde. Departamento de Ações Programáticas Estratégicas. Saúde mental no SUS: os centros de atenção psicossocial. Brasília: Ministério da Saúde, 2004.

Carneiro, N. G. Memórias do delírio: a construção da pessoa em processos reintegrados autogestionados. Curitiba, 2000. 150 f. Dissertação (Mestrado em Antropologia), Setor de Ciências Humanas, Letras e Artes, Universidade Federal do Paraná, Curitiba, PR.

CAstel, R. A ordem psiquiátrica: a idade de ouro do alienismo. Rio de Janeiro: Graal, 1978.

ClassificaÇão de Transtornos Mentais e de Comportamento da CID-10. Organização Mundial de Saúde. Porto Alegre: Artes Médicas, 1993, p. 5.

Di CiACCIA, A. Da fundação por um à prática feita por muitos. Psicoanálisis e Salud Mental. Curinga, Belo Horizonte, n. 13, set. 1999.

Foucault, M. Doença mental e psicologia. Rio de Janeiro: Tempo Brasileiro, 1968.

Goffman, I. Modelo médico e a hospitalização psiquiátrica: algumas notas sobre as vicissitudes das tarefas de reparação. São Paulo: Perspectiva, 1990.

LACAN, J. De uma questão preliminar para todo tratamento possível da psicose. In: Escritos. Rio de Janeiro: Zahar, 1998.

LAIng, R.; Cooper, D. Razón e violencia: una decada de pensamiento sartreano. Buenos Aires: Paidos, 1969.

Lucena Fernandes, R. Nem “entre vários”, nem “entre muitos. Correio 54 - Revista da Escola Brasileira de Psicanálise, nov. 2005, p. 39.

Miller, J.A. Saúde Mental e Ordem Pública. Curinga, Belo Horizonte, n. 13, p. 20-21, set. 1999. jan.mar 1994.

. A lógica da direção da cura psicanalítica. Opção Lacaniana, São Paulo, v. 9,

Pessotti, I. O século dos manicômios. São Paulo: Editora 34, 1996. 
Rego Barros, M. R. A prática lacaniana nas instituições: uma experiência de vários. $O p$ - confirmar ção Lacaniana, São Paulo, n. 37, p. 79, set. 2003.

Viganó, C. 25 anos depois, ainda. Mental, Barbacena, ano 2, n. 2, p. 11-25, jun. 2004.

Zenoni, A. Psicanálise e instituição. A segunda clínica de Lacan. Abrecampos, Belo Horizonte, Ano 1, n. 0, p. 19, 2000.

\section{Resumos}

(Del modelo asilar-manicomial al modelo de reabilitación psicossocial - tendrá un lugar para el psicoanalista en Salud Mental?)

Desde la sin razón al enfermo mental y al portador de trastornos mentales, a pesar de operarse desplazamientos importantes en las Instituciones de Salud Mental, el sujeto continua excluido. Se discute la propuesta de una institución que pueda sostener la lógica del no todo, del caso a caso, donde no se pueda escribir lo universal o formar conjunto. El psicoanálisis aplicado al campo de la salud mental podría ser formulado como una clínica del sujeto, fundamentado, no en la diversidad, sino en la singularidad de la relación del sujeto con su deseo y su goce.

Palabras claves: Psicoanálisis Aplicada, lógica del no todo, clínica de la psicosis, sujeto supuesto no saber

(Du modèle de l'asile - hôpital psychiatrique au modèle de la re-habilitation psychosociale - il y aura-t-il une place pour le psychanalyste en santé mentale?)

De la déraison au malade mental et au porteur de trouble mental, malgré les déplacements importants qui sont mis en place dans les Institutions de Santé Mentale, le sujet reste exclu. On discute la proposition d'une institution qui puisse soutenir la logique du pas-tout, du cas à cas, où on ne peut pas écrire l'universel ou former un tout. On présente la psychanalyse appliquée au champ de la Santé Mentale comme une clinique du sujet, fondée non pas sur la diversité mais plutôt sur la singularité de son rapport à son désir et à sa jouissance.

Mots clés: Psychanalyse appliquée, logique du pas-tout, clinique de la psychose, sujet supposé ne pas savoir

(From the asylum model to the psycho-social rehabilitation model - will there be a place for the psychoanalyst in mental health?)

From the mentally ill to the mentally handicapped, major displacements have been taking place in institutions and mental health clinics. In any case, however, patients remain excluded. This article discusses an institutional setting which operates from a logic of the not-all, case by case, where the universal cannot be written or represented 
as a fixed set of factors. Psychoanalysis applied to the mental health field is presented as a clinic of the subject, founded not on diversity but on the singularity of its relationship with desire and jouissance.

Key words: Applied Psychoanalysis, logic of the not-all, clinic of psychosis, subject supposed-to-know

Versão inicial recebida em dezembro de 2006 Versão aprovada para publicação em maio de 2008

\section{Nancy Greca de Oliveira Carneiro}

Psicanalista; mestre em Antropologia Social; professora do Curso de Psicologia da Pontifícia Universidade Católica do Paraná - PUC-PR (Curitiba, PR, Brasil); membro do Grupo de Pesquisa Aspectos Psíquicos e Psicossociais do ser Humano em Desenvolvimento, na linha de pesquisa de Psicopatologia Fundamental da Pontifícia Universidade Católica do Paraná - PUCPR (Curitiba, PR, Brasil).

Rua Imaculada Conceição, 1155 - Prado Velho

80215-901 Curitiba, PR, Brasil

Fonefax: (41) 3271-1591

e-mail: nancy.carneiro@pucpr.br 